\title{
Development of New Photosensitive Low CTE Materials
}

\author{
Takashi Doi, Takaaki Uno, Isao Nishimura, and Eiji Hayashi* \\ * Advanced Materials Research Laboratories, JSR Corporation, \\ 100 Kawajiri-cho, Yokkaichi, Mie 510-8552, Japan \\ Eiji_Hayashi@jsr.co.jp
}

\begin{abstract}
We developed a new negative type photosensitive material with the phenolic resin. The film of the material cured at $260^{\circ} \mathrm{C}$ showed low coefficients of thermal expansion (CTE), low residual stress and good heat resistance. And the material exhibited good lithography performance. Thus, we expect application of this material to 3D packaging which requires low CTE and low residual stress by low temperature curing.
\end{abstract}

Keyword: Negative type photosensitive material, low CTE, low residual stress

\section{Introduction}

Silicon-based semiconductor integrated circuits have been highly developed towards miniaturization and high integration according to Moore's Law [1-2]. However, it was believed that within several years the further miniaturization may reach its limit because of physical and economical factors. Recently, Through-Silicon Via (TSV) technology has been actively developed to realize three-dimensional (3D) packaging, basing on the idea that high integration can be accomplished by mounting chips sterically [3]. Accordingly, ultrathin wafers are required for downsizing, high-frequency operation, and reducing power consumption. The wafer thickness for $3 \mathrm{D}$ packaging will be reduced to around $5 \mu \mathrm{m}$, as indicated by ITRS 2011 [4].

Most of existing materials have CTE within the range of 40 to $80 \mathrm{ppm} /{ }^{\circ} \mathrm{C}$, which are much higher than that of silicon wafer $\left(4 \mathrm{ppm} /{ }^{\circ} \mathrm{C}\right)$ and copper wiring $\left(17 \mathrm{ppm} /{ }^{\circ} \mathrm{C}\right)$. When such existing materials are coated onto silicon wafers and cured, residual stress and warpage arising from the CTE mismatch between materials and wafers deteriorate reliability of products. Therefore, photosensitive low CTE materials such as negative and positive type photosensitive polyimides (PSPIs) have been studied to solve this problem [5-6].

Figure 1 shows correlations of CTE (vertical axis) and curing temperature (horizontal axis). Conventional existing materials are on the trade-off line in the figure. For example, high temperature-curing type PSPIs have low CTE (about $20 \mathrm{ppm} /{ }^{\circ} \mathrm{C}$ ). It is known that low CTE strongly depends on rigidity and orientation of the molecular backbone. On the other hand, the PSPIs require high curing temperature, typically more than $300^{\circ} \mathrm{C}$. Because of the high temperature, there are concerns about damage to low heat resistant substrates and other materials [7]. Therefore, we started development of low temperature-curing type photosensitive low CTE materials. Properties and molecular designs of the base resin are outlined in Figure 2.

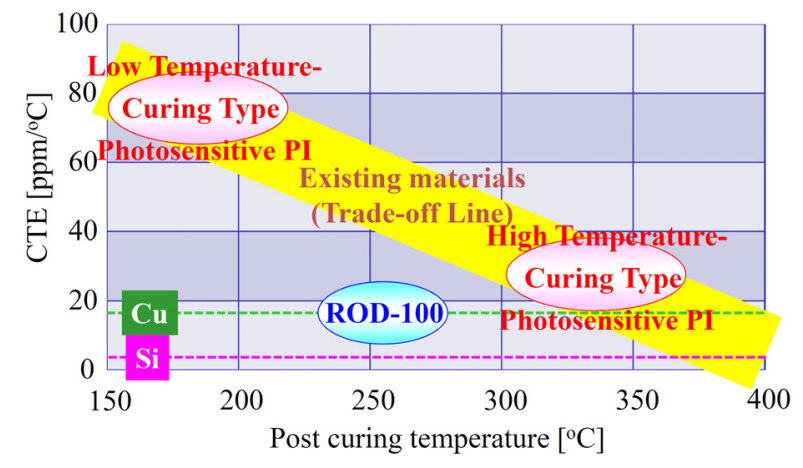

Figure 1. Correlations of CTE and curing temperature 


\begin{tabular}{|c|c|}
\hline $\begin{array}{c}\text { Properties } \\
\text { performance }\end{array}$ & $\begin{array}{c}\text { Molecular designs } \\
\text { groups such as phenol }\end{array}$ \\
\hline Low temperature-curing & $\begin{array}{c}\text { Heat reactivity of the base } \\
\text { resin at low temperature }\end{array}$ \\
\hline $\begin{array}{c}\text { Low CTE and } \\
\text { low residual stress }\end{array}$ & Rigidity and orientation \\
\hline
\end{tabular}

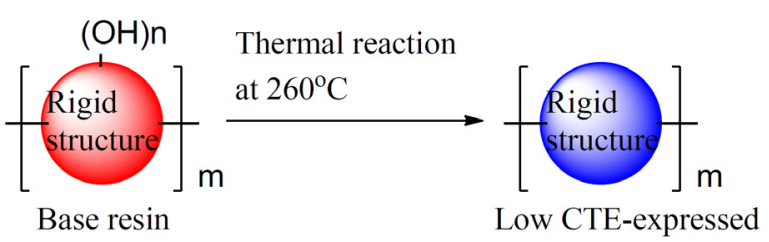

Figure 2. Properties and molecular designs to give to the base resin

Resins were synthesized according to the molecular designs, and evaluated. As a result, we succeeded in development of the low temperature-curing type photosensitive low CTE material, ROD-100, which has good properties beyond the trade-off line as shown in Figure 1. In this paper, we report on validity of the molecular designs and the data of film properties and lithography performance.

\section{Experimental}

\subsection{Synthesis of resins}

At first, we focused on the certain kind of phenol derivatives having rigidity and alkali-solubility as a monomer. Because monomer exists in several isomeric forms, resins were prepared by oxidative coupling polymerization of each isomer as shown in Scheme1. Mw and given properties of the resins are summarized in Table 1.

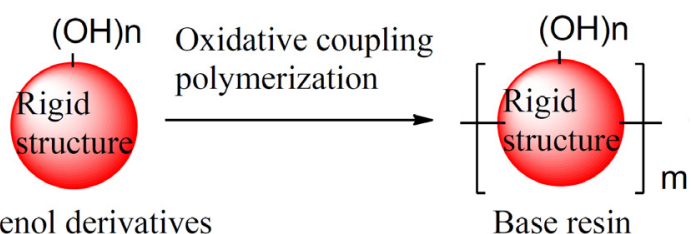

Phenol derivatives

Base resin

Scheme 1. Synthesis of resins

Table 1. Mw and given properties of the resins

\begin{tabular}{|c|c|c|c|c|}
\hline Resin & Mw & Rigidity & $\begin{array}{c}\text { Heat } \\
\text { reactivity }\end{array}$ & $\begin{array}{c}\text { Alkali- } \\
\text { solubility }\end{array}$ \\
\hline$\underline{\mathbf{A}}$ & 50,000 & $\bigcirc$ & $\bigcirc$ & $\bigcirc$ \\
\hline$\underline{\mathbf{B}}$ & 36,000 & $\triangle$ & $\triangle$ & $\bigcirc$ \\
\hline$\underline{\mathbf{C}}$ & 17,000 & $\triangle$ & $\bigcirc$ & $\bigcirc$ \\
\hline$\underline{\mathbf{D}}$ & 20,000 & $\times$ & $\bigcirc$ & $\bigcirc$ \\
\hline
\end{tabular}

2.2. Preparation of the photosensitive resin composition

The photosensitive resin varnish was prepared by adding the resin, the crosslinking agent and the photo acid generator (PAG) to mixed solvent of Ethylene glycol monomethyl ether (EGME) and Propylene glycol monomethyl ether acetate (PGMEA)

\subsection{Preparation of cured films}

Table 2 shows standard process conditions to evaluate film properties and lithography performance.

Table 2. Standard process conditions for evaluation of ROD-100

\begin{tabular}{|c|c|}
\hline Process & Conditions \\
\hline Primer treatment & $\begin{array}{l}\text { 3-aminopropyltrimethoxysilane } \\
\qquad 150^{\circ} \mathrm{C} / 5 \mathrm{~min}\end{array}$ \\
\hline Film thickness & $\begin{array}{c}3 \mu \mathrm{m} \text { (For lithography) } \\
10 \mu \mathrm{m} \text { (For film properties) }\end{array}$ \\
\hline Prebake & $90^{\circ} \mathrm{C} / 3 \mathrm{~min}$ \\
\hline $\begin{array}{c}\text { Exposure } \\
(\mathrm{g}, \mathrm{h}, \mathrm{i}-\text { line mixed })\end{array}$ & $\begin{array}{c}500 \mathrm{~mJ} / \mathrm{cm}^{2}(3 \mu \mathrm{m}) \\
1000 \mathrm{~mJ} / \mathrm{cm}^{2}(10 \mu \mathrm{m})\end{array}$ \\
\hline Post exposure bake & $95^{\circ} \mathrm{C} / 7.5 \mathrm{~min}$ \\
\hline Development & $60 \mathrm{sec} / 2.38 \mathrm{wt} \% \mathrm{TMAH}$ \\
\hline Rinse & $60 \mathrm{sec} / \mathrm{DI}$ water \\
\hline Post cure & $\begin{array}{c}30^{\circ} \mathrm{C}->260^{\circ} \mathrm{C} / 60 \mathrm{~min} \\
\left(\text { Rate: } 10^{\circ} \mathrm{C} / \mathrm{min}\right)\end{array}$ \\
\hline
\end{tabular}

2.4. Evaluation methods of thermal, mechanical and adhesion properties

Evaluation methods of thermal, mechanical and adhesion properties are summarized in Table 3 .

Table 3. Evaluation methods of film properties

\begin{tabular}{|c|c|}
\hline Items & Methods \\
\hline $\begin{array}{c}\text { Glass Transition } \\
\text { Temperature }(\mathrm{Tg})\end{array}$ & TMA method \\
\hline CTE $\left(-65^{\circ} \mathrm{C}<->150^{\circ} \mathrm{C}\right)$ & TMA method \\
\hline $\begin{array}{c}\text { Thermal Decomposition } \\
\text { Temperature }\end{array}$ & $\begin{array}{c}\text { TGA method } \\
10^{\circ} \mathrm{C} / \text { min in } \mathrm{N}_{2}\end{array}$ \\
\hline Tensile Strength & Tension test \\
\hline Elastic Modulus & On Si wafer \\
\hline Residual Stress & Cross-cut tape test \\
On Si wafer
\end{tabular}

\subsection{Evaluation of chemical resistance}

Cured films on silicon wafers were immersed in test solvents at room temperature for $10 \mathrm{~min}$. After that the films were washed with water and 
dried at room temperature. By the film thickness measurement before and after dipping, the change ratio was calculated. In addition, the appearance was observed with an optical microscope

\section{Results and Discussion}

\subsection{Resin screening}

We compared residual stress and CTE of the resins shown in Table 1 without any additives. Films were prepared by curing at $260^{\circ} \mathrm{C}$ for $60 \mathrm{~min}$ after prebaking. The results are summarized in Table 4.

Table 4. Residual stress and CTE of the synthesized resins

\begin{tabular}{|c|c|c|}
\hline Resin & Residual stress & CTE \\
\hline$\underline{\mathbf{A}}$ & $8 \mathrm{MPa}$ & $9 \mathrm{ppm} /{ }^{\circ} \mathrm{C}$ \\
\hline$\underline{\mathbf{B}}$ & $9 \mathrm{MPa}$ & $23 \mathrm{ppm} /{ }^{\circ} \mathrm{C}$ \\
\hline$\underline{\mathbf{C}}$ & $10 \mathrm{MPa}$ & $23 \mathrm{ppm} /{ }^{\circ} \mathrm{C}$ \\
\hline$\underline{\mathbf{D}}$ & $42 \mathrm{MPa}$ & $62 \mathrm{ppm} /{ }^{\circ} \mathrm{C}$ \\
\hline
\end{tabular}

The resin $\underline{\mathbf{A}}$ which satisfied all molecular design items showed the lowest residual stress and CTE. As a result, validity of the molecular design was confirmed. Table 5 shows various properties of the resin $\underline{\mathbf{A}}$.

Table 5. Various properties of the resin $\underline{\mathbf{A}}$

\begin{tabular}{|c|c|c|}
\hline \multirow{4}{*}{$\begin{array}{c}\text { Resin } \\
\text { Properties }\end{array}$} & $\begin{array}{c}\text { Alkali-solubility } \\
(2.38 \mathrm{wt} \% \text { TMAHaq })\end{array}$ & Properties \\
\cline { 2 - 3 } & Transmittance & $\begin{array}{c}\text { i-line non- } \\
\text { transparent }\end{array}$ \\
\hline \multirow{4}{*}{$\begin{array}{c}\text { Film } \\
\text { Properties }\end{array}$} & Tg & $>400^{\circ} \mathrm{C}$ \\
\cline { 2 - 3 } & CTE & $9 \mathrm{ppm} /{ }^{\circ} \mathrm{C}$ \\
\cline { 2 - 3 } & \begin{tabular}{c} 
Thermal \\
\cline { 2 - 3 }
\end{tabular} & $\begin{array}{c}430^{\circ} \mathrm{C} \\
(5 \% 10 \mathrm{oss})\end{array}$ \\
\cline { 2 - 3 } & Tensile Strength & $130 \mathrm{MPa}$ \\
\cline { 2 - 3 } & Elastic Modulus & $4.4 \mathrm{GPa}$ \\
\cline { 2 - 3 } & Residual Stress & $8 \mathrm{MPa}$ \\
\hline
\end{tabular}

The resin $\underline{\mathbf{A}}$ exhibited good solubility for alkali developing solution (2.38wt\% TMAHaq). The cured film showed not only low CTE and low residual stress, but also good heat resistant. Then we prepared the photosensitive resin composition, and evaluated as a negative type resist, ROD-100.

\subsection{Film properties}

Thermal properties, mechanical properties and residual stress of the resin composition are summarized in Table 6.

Table 6. Film properties of ROD-100

\begin{tabular}{|c|c|}
\hline Items & ROD -100 \\
\hline $\mathrm{Tg}$ & $>300^{\circ} \mathrm{C}$ \\
\hline $\mathrm{CTE}$ & $18 \mathrm{ppm} /{ }^{\circ} \mathrm{C}$ \\
\hline $\begin{array}{c}\text { Thermal } \\
\text { Decomposition Temp. }\end{array}$ & $352^{\circ} \mathrm{C}(5 \%$ loss $)$ \\
\hline Tensile Strength & $90 \mathrm{MPa}$ \\
\hline Elastic Modulus & $5.2 \mathrm{GPa}$ \\
\hline Residual Stress & $13 \mathrm{MPa}$ \\
\hline
\end{tabular}

The CTE of ROD-100 was $18 \mathrm{ppm} /{ }^{\circ} \mathrm{C}$, and it was equal to that of copper $\left(17 \mathrm{ppm} /{ }^{\circ} \mathrm{C}\right)$. In addition, the residual stress was also low (13MPa). However, film properties of ROD-100 got a little worse as a whole compared with those of the resin

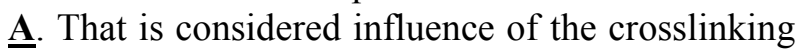
agent to give photosensitivity. Accordingly, we are examining the laser micro fabrication of the resin without crosslinking agents as a next study.

\subsection{Chemical resistance}

Table 7 indicates results of chemical resistance. ROD-100 showed good chemical resistance to various process chemicals such as propylene glycol monomethyl ether (PGME) / PGMEA, $N$-methylpyrrolidone (NMP), isopropyl alcohol (IPA) and dimethyl sulfoxide (DMSO).

Table 7. Chemical resistance of ROD-100

\begin{tabular}{|c|c|c|c|}
\hline \multirow{2}{*}{ Chemicals } & \multirow{2}{*}{ Conditions } & \multicolumn{2}{|c|}{ ROD-100 } \\
\cline { 3 - 4 } & $\begin{array}{c}\text { Swelling } \\
\text { ratio }\end{array}$ & Appearance \\
\hline $\begin{array}{c}\text { PGME / } \\
\text { PGMEA }\end{array}$ & \multirow{3}{*}{$\begin{array}{c}\text { r.t./10mi } \\
\mathrm{n}\end{array}$} & $101 \%$ & OK \\
\cline { 1 - 2 } NMP & $100 \%$ & OK \\
\cline { 1 - 2 } IPA & & $101 \%$ & OK \\
\hline DMSO & & $101 \%$ & OK \\
\hline
\end{tabular}

\subsection{Adhesion}

Table 8 exhibits results of adhesion properties by cross-cut tape test. ROD-100 had good adhesion properties to bare silicon wafer and $\mathrm{Al}$ substrate with the primer treatment. 
Table 8. Adhesion properties of ROD-100

\begin{tabular}{|c|c|}
\hline Substrates & $\begin{array}{c}\text { ROD-100 } \\
\text { (with the primer treatment) }\end{array}$ \\
\hline Bare Silicon & $100 / 100$ \\
\hline $\mathrm{Al}$ & $100 / 100$ \\
\hline
\end{tabular}

100/100: No peel was confirmed.

\subsection{Lithography performance}

Then, lithography performance of ROD-100 was evaluated. Figure 3 shows SEM images of the patterns before and after post curing. As a result, it was confirmed that the size of the pattern was almost same as the size of the mask opening. And, shape change of the patterns after post curing was not observed.

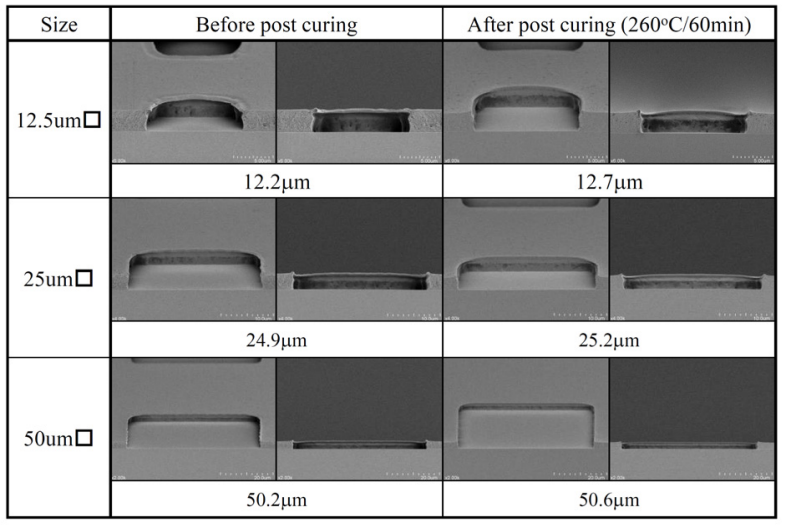

Figure 3. SEM images of the patterns before and after post curing

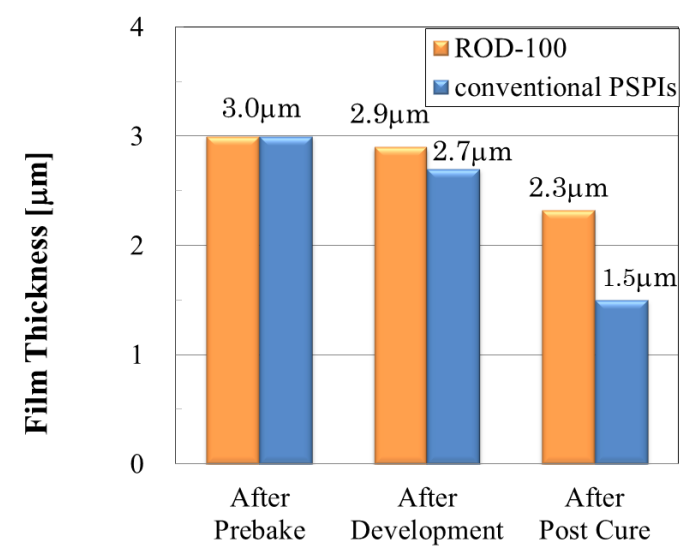

Figure 4. Film thickness change through process
3.6. Film thickness change through the process

Figure 4 indicates film thickness change of ROD-100 in each process. When the film thickness after prebaking was $3.0 \mu \mathrm{m}$, it got $2.9 \mu \mathrm{m}$ and $2.3 \mu \mathrm{m}$ after developing and curing, respectively. As the film thickness change of ROD-100 through the process was c.a. 24\%, it was smaller than that of conventional PSPIs (c.a. 40-50\%).

\section{Conclusion}

We developed the new negative type photosensitive material with the phenolic resin. The film of the material cured at $260^{\circ} \mathrm{C}$ showed low CTE, low residual stress and good heat resistance. And the material exhibited good lithography performance. Thus, we expect application of this material to 3D packaging which requires low CTE and low residual stress by low temperature curing.

\section{References}

1. H. Ito, J. Photopolym. Sci. Technol. 20 (2007) 319.

2. H. Ito, J. Photopolym. Sci. Technol. 21 (2008) 475.

3. P. S. Andry, C. K. Tsang, S. L. Wright, B. Dang, C. S. Patel, B. C. Webb, J. Maria, E. J. Sprogis, S. K. Kang, R. J. Polastre, R. R. Horton and J. U. Knickerbocker, $I B M$ Journal of Research and Development, 52 (2008) 611.

4. ITRS. "International Technology Roadmap for semiconductors (ITRS 2011)". http://www.itrs.net

5. T. Higashihara, Y. Shibasaki, M. Ueda, $J$. Photopolym. Sci. Technol. 25 (2012) 9.

6. M. Hasegawa, Y. Tanaka, K. Koseki, A. Tominaga, J. Photopolym. Sci. Technol. 19 (2006) 285.

7. J. Yota, H. Ly, R. Ramanathan, S. Hsiang-Chih, D. Barone, T. Nguyen, K. Katoh, M. Ohe, R. L. Hubbard, K. Hicks, IEEE Transactions on Semiconductor Manufacturing, 20(3) (2007) 323. 